\section{Diversity of Bacterial and Fungal Communities in Wheat Straw Compost for Agaricus bisporus Cultivation}

\author{
Guangtian Cao ${ }^{1}$
}

Department of Horticulture, Zhejiang Academy of Agricultural Sciences, Hangzhou 310021, Zhejiang, China; and College of Standardisation, China Jiliang University, Hangzhou 310018, Zhejiang, China

\section{Tingting Song ${ }^{1}$, Yingyue Shen, Qunli Jin, Weilin Feng, Lijun Fan, and Weiming Cai ${ }^{2}$ \\ Department of Horticulture, Zhejiang Academy of Agricultural Sciences, Hangzhou 310021, Zhejiang, China}

Additional index words. microbiota, thermophilic, composting, microflora, 16S rRNA sequencing, ITS sequencing

\begin{abstract}
The Agaricus genus represents the most popular edible mushroom in the world. Wheat straw often is used as the substrate for mushroom cultivation following pretreatment to degrade the lignocellulosic biomass in agricultural waste. In this study, we investigated the changes in bacterial and fungal microflora of wheat straw substrate during different phases of composting. We collected samples of the raw material (M1), phase I aerobic fermentation (F1, F2, F3), and phase II after-fermentation (AF1) for high-throughput 16S rRNA and internal transcribed spacer (ITS) sequencing to analyze the microbial diversity in the substrate during composting. Our data revealed that among the five stages, 365 operational taxonomic units (OTUs) were shared, with Firmicutes, Proteobacteria, and Actinobacteria being the predominant bacterial phyla. In addition, Thermobispora, Thermopolyspora, Ruminiclostridium, Thermobacillus, and Bacillus were the predominant genera in F3 and AF1, with the species Thermobispora bispora and Pseudoxanthomonas taiwanensis being predominant in F2. Both principal component analysis (PCA) and nonmetric multidimensional scaling (NMDS) plots showed that the bacterial communities of five stages could be distinguished from each other based on their composting time. The Shannon and Simpson indexes of F2 were lower than M1 $(P<0.05)$, and the clustering dendrogram showed that the bacterial communities in AF1 were similar to F3, with Micromonosporaceae, Streptosporaceae, Thermomonosporaceae, and Vulgatibacteraceae representing the differential bacterial families by linear discriminant analysis with effect size (LEfSe) analysis. The analysis of fungal communities showed that 384 OTUs were common among the five stages, with 1054 and 454 OTUs unique to M1 and AF1, respectively. Ascomycota and Basidiomycota were the two predominant phyla in all stages, and Chytridiomycota was predominant in F2, F3, and AF1 stages. PCA and NMDS plots showed that the clusters of F2 and AF1 were more dispersed than the other stages. No differences were observed in alpha diversity between the stages, and samples of F1, F2, and F3 were closer to AF1 in the clustering dendrogram. By LEfSe analysis, Mycothermus thermophilus, Gonapodya polymorpha, and Phaeophleospora_eugeniae were identified as the predominant fungal species in AF1.
\end{abstract}

China, Malaysia, India, and Ireland are leading in global mushroom production (Hanafi et al., 2018). Agaricus genus is the most popular edible mushroom in the world,

Received for publication 25 Sept. 2018. Accepted for publication 25 Nov. 2018.

This work was supported by the "China's Ministry of Agriculture, Agricultural Public Welfare Industry Research (201503137)" and National Science Foundation of Zhejiang Province of China (LQ16C150004). We also thank Yu Shangting for help in obtaining the wheat straw substrates used in this work.

${ }^{1}$ These authors contributed equally to this work. ${ }^{2}$ Corresponding author. E-mail: caiwm527@126. com.
(A. bisporus) production, which more studies are needed to conducted.
Wheat straw is a lignocellulosic substrate composed of cellulose, hemicellulose, and lignin and is the second largest biomass feedstock in the world (Saha and Cotta, 2006). Hua et al. (2016) found that microorganisms could enzymatically digest the cell walls of plant biomass. Among the lignocellulolytic and nonlignocellulolytic microbes present on natural substrates, the former shows biodegradability (Tejirian and $\mathrm{Xu}$, 2010). In a recent study, Proteobacteria was reported to be the dominant phylum in different fermentative stages of lignocellulosic material (Xiao et al., 2018). Compared with chemical and physical biomass pretreatment methods, biological pretreatment demonstrates an outstanding delignification ability with low energy consumption and the absence of toxic substances. During aerobic fermentation, temperature in the wheat straw substrate varies over time. Microbial activity leads to temperature increments, as their metabolic activity produces energy by the codigestion of lignocellulosic biomass. In addition, ligninolytic fungi produce highly active ligninolytic enzymes, which further delignify the plant biomass (Ćilerdžić et al., 2017; Rouches et al., 2017; Saparrat and Guillén, 2005; Šnajdr and Baldrian, 2006). A study confirmed that the micro-organisms degrade about $40 \%$ of the dry matter of in the compost, and the dry matter holds potential valuable nutrients of A. bisporus (Straatsma et al., 1994). Thus, changes in the Agaricus sp. of fungi are crucial to mushroom production. In this study, we investigated the changes in microflora of the wheat straw substrate used for the cultivation of $A$. bisporus.

\section{Materials and Methods}

Preparation of wheat straw substrate. Wheat straw was composted in the ventilation fermentation chamber of the Horticulture Institute, Zhejiang Academy of Agricultural Sciences in 2016. Composting windrows $(15 \times 2 \times 1.8 \mathrm{~m})$ consisted of $600 \mathrm{~kg}$ of wheat straw mixture, $40 \mathrm{~kg}$ of rapeseed cake, $15 \mathrm{~kg}$ of $\mathrm{CaSO}_{4} \cdot 2 \mathrm{H}_{2} \mathrm{O}, 5 \mathrm{~kg}$ of $\mathrm{Ca}\left(\mathrm{H}_{2} \mathrm{PO}_{4}\right)_{2} \cdot \mathrm{H}_{2} \mathrm{O}, 4 \mathrm{~kg}$ of $\left(\mathrm{NH}_{4}\right)_{2} \mathrm{SO}_{4}$, and $6 \mathrm{~kg}$ of urea $\left(\mathrm{CH}_{4} \mathrm{~N}_{2} \mathrm{O}\right)$.

Sample collection. The substrate mixture was moistened by manual spraying, and $\approx 200 \mathrm{~g}$ of samples (M1) were collected in triplicate before initiating the self-heating composting phase. To enhance the composting process, the windrows were turned on the fifth (F1), ninth (F2), and 12th (F3) day of Phase I. During turning, water and $\mathrm{CaCO}_{3}$ were added manually to maintain the moisture content $(60 \%$ to $70 \%)$ and $\mathrm{pH}(6-8)$. At the end of each stage, samples $(\approx 200 \mathrm{~g}$ each) were collected in triplicate. The three samples collected at five different points (at all depths from the four edges and center) were pooled and mixed thoroughly. Phase II, consisting of $6 \mathrm{~d}$, was characterized by a rapid increase in temperature up to $60^{\circ} \mathrm{C}$ for $8-9 \mathrm{~h}$, followed by stabilization of the compost temperature to 45 to $50{ }^{\circ} \mathrm{C}$ for $5 \mathrm{~d}$, and 
A

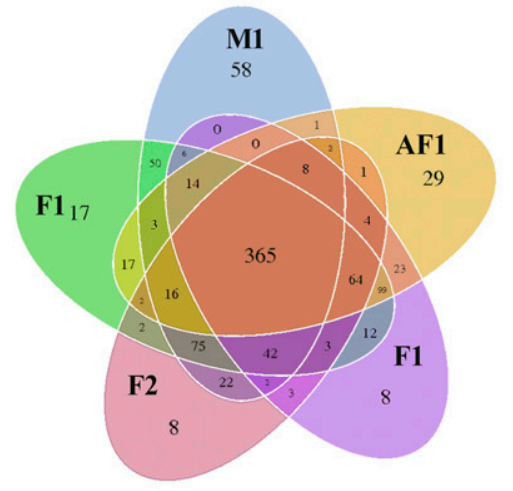

B

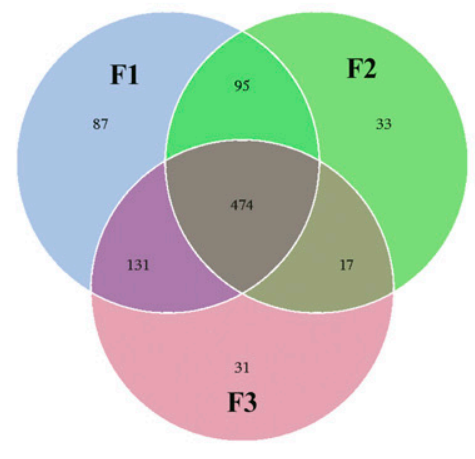

C

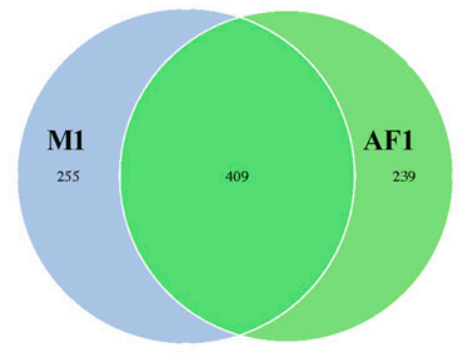

D

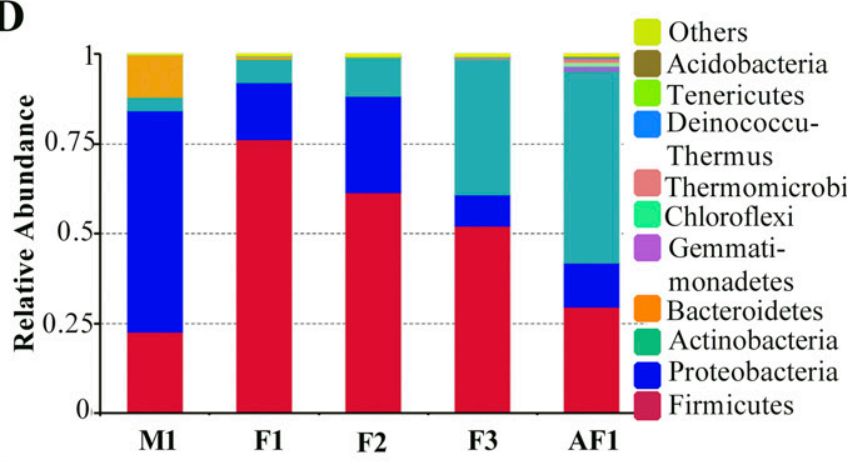

F
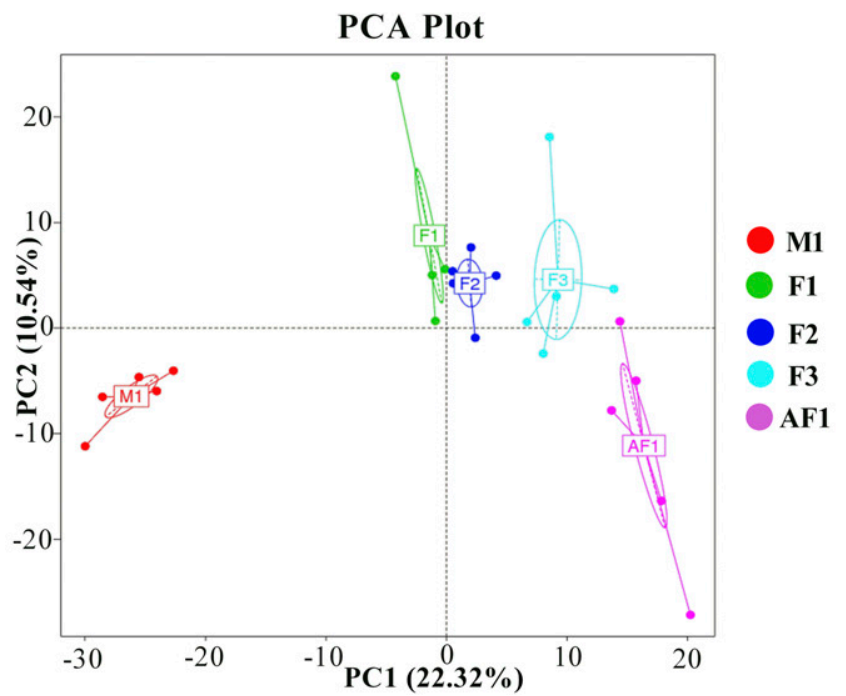

E

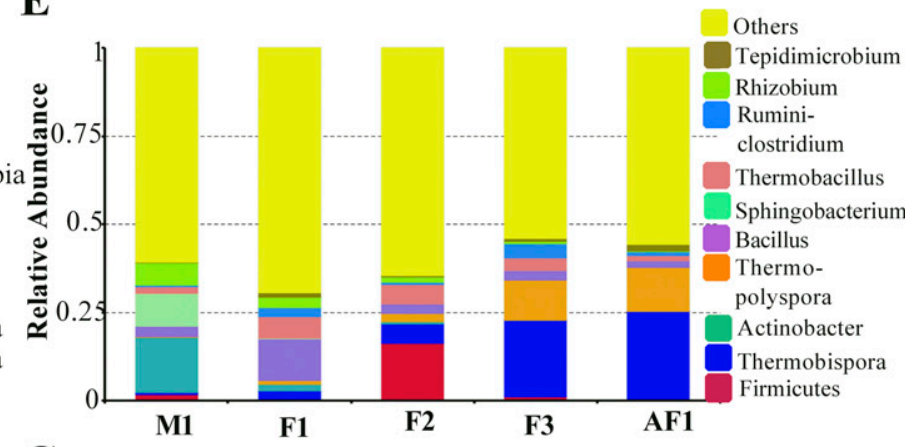

G

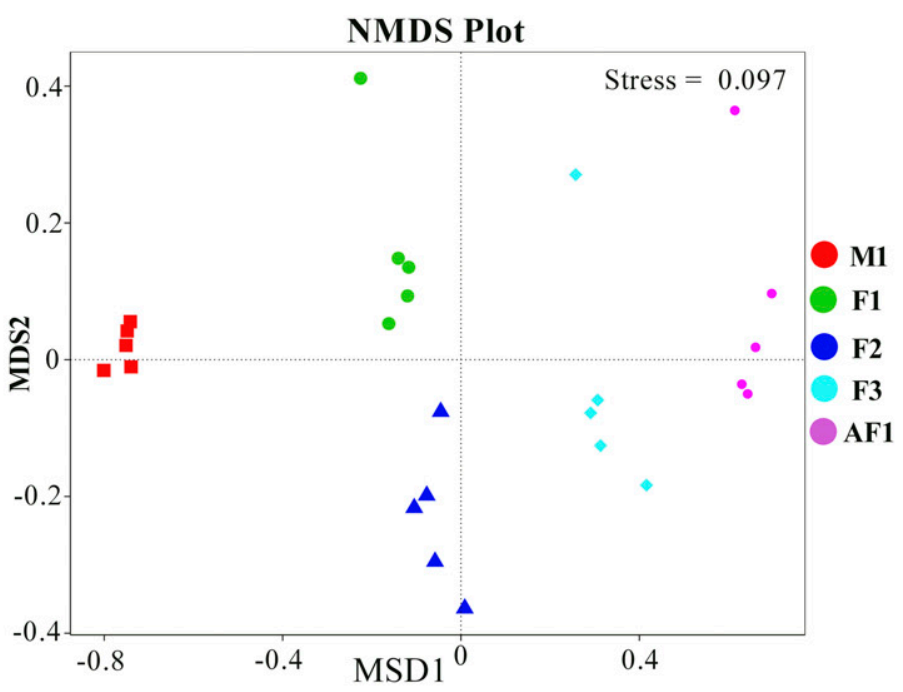

Fig. 1. Operational taxonomic unit analysis of bacterial communities in wheat straw substrates (A-C). Top 10 bacterial phyla (D) and genera (E) of bacterial communities in wheat straw substrates. Principal component analysis (PCA) (F) and nonmetric multidimensional scaling (NMDS) (G) plots of bacterial communities in wheat straw substrates.

gradual cooling to $25^{\circ} \mathrm{C}$. When the composting process was complete, samples (AF1) were collected as described for further analysis. Before analysis, all samples were dried using a vacuum freeze dryer (VirTis Company, New York, NY) and stored at $-80^{\circ} \mathrm{C}$.

High-throughput sequencing of $16 \mathrm{~S} r R N A$. Total genomic DNA was extracted from a 0.5 -g mixture of wheat straw using the Power Soil DNA Extraction Kit (Mo Bio Laboratories Inc., Carlsbad, CA) according to manufacturer's instructions. The $16 \mathrm{~S}$ rRNA amplicon sequencing was performed as described previously with modifications (Sun et al., 2018; Xiao et al., 2016). To summarize in brief, the specific primer pair $515 \mathrm{~F}$ $\left(5^{\prime}-\right.$ GTGCCAGCMGCCGCGGTAA-3') and 806R (5'-GGACTACHVGGGTWTCTAAT-3') targeting the V4 hypervariable regions of $16 \mathrm{~S}$ rRNA were used on the Illumina MiSeq platform at Novogene Cooperation (Beijing, China), with the HiSEq. 2500 (PE250) sequencing system. The ITS amplicon sequencing used the specific primer pair ITS1-F $\left(5^{\prime}-\mathrm{CT}\right.$ TGGTCATTTAGAGGAAGTAA- $3^{\prime}$ ) and ITS1R (5'-GCTGCGTTCTTCATCGATGC-3').
The split_libraries_fastq.py script in Quantitative Insights Into Microbial Ecology (QIIME V1.7.0) was used for the filtering of raw reads. OTUs with $97 \%$ similarity were clustered according to the UPARSE method.

Biostatistics analysis. Unweighted and weighted UniFrac (QIIME) analysis were used to compare the similarity or difference among the different wheat straw sequencing libraries. The Wilcox test was used to assess alpha and beta diversity parameters. PCA and NMDS analyses were performed using $R$ 
software (Version 2.15.3; Foundation for Statistical Computing, Vienna, Austria). LEfSe tool was accessed online at http:// huttenhower.sph.harvard.edu/galaxy/.

\section{Results}

OTUs analysis of bacterial communities. Among the five stages, 365 core OTUs were observed (Fig. 1A). M1, F1, F2, F3, and AF1 had $58,17,8,8$, and 29 unique OTUs, respectively. F1, F2, and F3 shared 474 OTUs (Fig. 1B). M1 and AF1 shared 409 OTUs, whereas 255 and 239 OTUs were unique in $\mathrm{M} 1$ and $\mathrm{AF} 1$, respectively (Fig. 1C).

Top 10 bacterial phyla and genera. Figure 1D lists the top 10 phyla identified by relative abundance in the five stages of the substrate. Firmicutes, Proteobacteria, and Actinobacteria were the top three phyla. Moreover, Bacteroidetes was also dominant in M1. Interestingly, the relative abundance of Firmicutes increased significantly to the dominant phyla at F1 and then decreased gradually at F2-3 and AF, and Actinobacteria increased over time. Orders of Bacillales, Clostridiales, Rhizobiales, and Streptosporangiales dominated different fermentation stages, with the Streptosporangiales increasing significantly over time (Supplemental Fig. 1A).

Figure 1E lists the top 10 genera based on relative abundance, and only a few of them were shared across the five stages of the substrate. Actinobacter, Bacillus, Sphingobacterium, and Rhizobium were the top four genera in M1. Bacillus, Thermobacillus, Rhizobium, and Ruminiclostridium were the top four genera in F1. Firmicutes, Thermopolyspora, Thermobispora, Bacillus, and Thermobacillus were the top five genera in F2, and Thermobispora, Thermopolyspora, Ruminiclostridium, Thermobacillus, and $\mathrm{Ba}$ cillus were the top five genera in $\mathrm{F} 3$ and AF1.

PCA and NMDS plots of bacterial communities. The PCA plot showed that the microflora community of five stages could be distinguished from each other according to the time point, and the M1 samples were separated from the fermentation and afterfermentation phase samples (Fig. 1F). Similarly, the NMDS plot also confirmed the aforementioned results, which the samples from the five stages could be distinguished from each other.

Dominant bacterial species. The top 10 bacterial species identified in the five stages of the substrate are listed in Fig. 2. Bacterial species identified in straw substrate F2 accounted for $22 \%$ of the bacterial composition, which was less than $20 \%$ for the samples from the other stages. Acinetobacter sp. NIPH 2171, Rhizobium larrymoorei, and Acinetobacter schindleri were the predominant species in M1, whereas F3 and AF1 were dominated by Thermobispora bispora. Bacillaceae bacterium NS1-3 and Bacillus thermocloaceae represented about $50 \%$ of the bacterial species identified in F1. In addition, Pseudoxanthomonas taiwanensis was the predominant species in F2.

Alpha and beta diversity of bacterial communities. The parameters of alpha diversity at the five stages are listed in Fig. 3AC. The Shannon index of F2 was significantly lower than that of M1 or F1 $(P<0.05)$, and M1 had an increasing trend compared with $\mathrm{F} 3$ and $\mathrm{AF} 1(P=0.052, P=0.087)$. Likewise, the Simpson index of F2 was significantly lower than that of M1 $(P<0.05)$ and had a decreasing trend than F1 $(P=0.066)$. Furthermore, the PD_Whole tree of F2 was significantly $(P<0.05)$ lower than that of $F 1$.

Based on the unweighted UniFrac distance, F2 was significantly greater $(P<0.05)$ than F1 (Fig. 3D), and the cluster dendrogram of the relative abundance in phylum level showed that AF1 was similar to F1 or F3 (Fig. 3F). Based on the weighted UniFrac distance, F2 were significantly greater $(P<$
0.05) than the other stages (Fig. 3E), and the cluster dendrogram showed that AF1 was similar to F3, whereas M1 was distinguished from the other phases (Fig. 3G). Interestingly, with time the relative abundance of the Firmicutes phylum decreased, whereas that of Actinobacteria increased.

LEfSe analysis and ternary plot of bacterial communities. The cladogram depicts the fermentative microbial strains distinguishing the five stages (Fig. 4A). As expected, M1 was represented by strains of Bacteroidetes and Proteobacteria phyla, consisting the Sphingobacteriaceae family in the former, and Enterobacteriaceae, Moraxellaceae and Psedomonadaceae families in the latter. The AF1 stage included strains from the Actinobacteria and Proteobacteria phyla, in which the former was represented by the families Micromonosporaceae, Streptosporaceae, and Thermomonosporaceae,
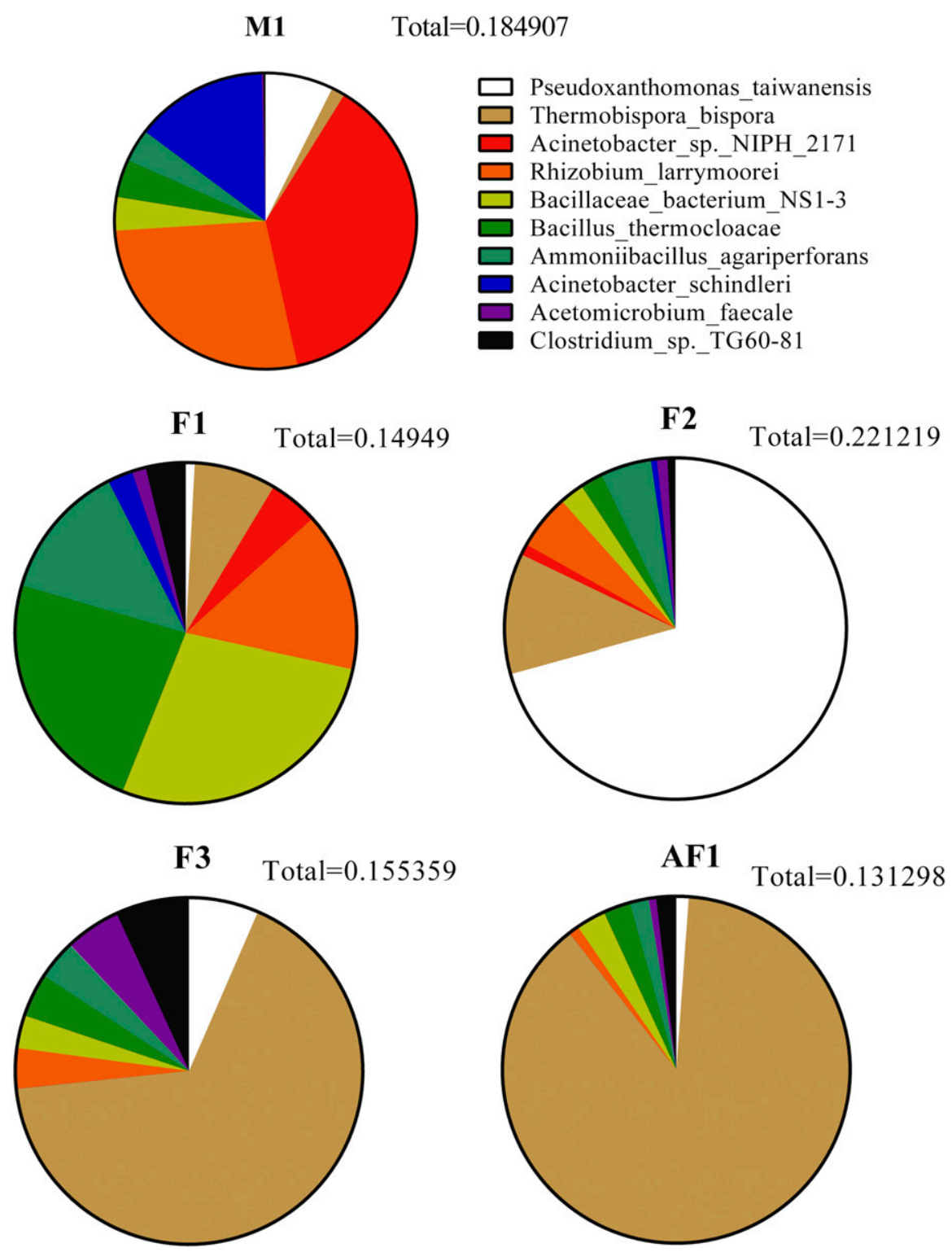

Fig. 2. The top 10 bacterial species identified in the five stages of wheat straw substrate. "Total (\%)" represents the known species in all the sequences. 


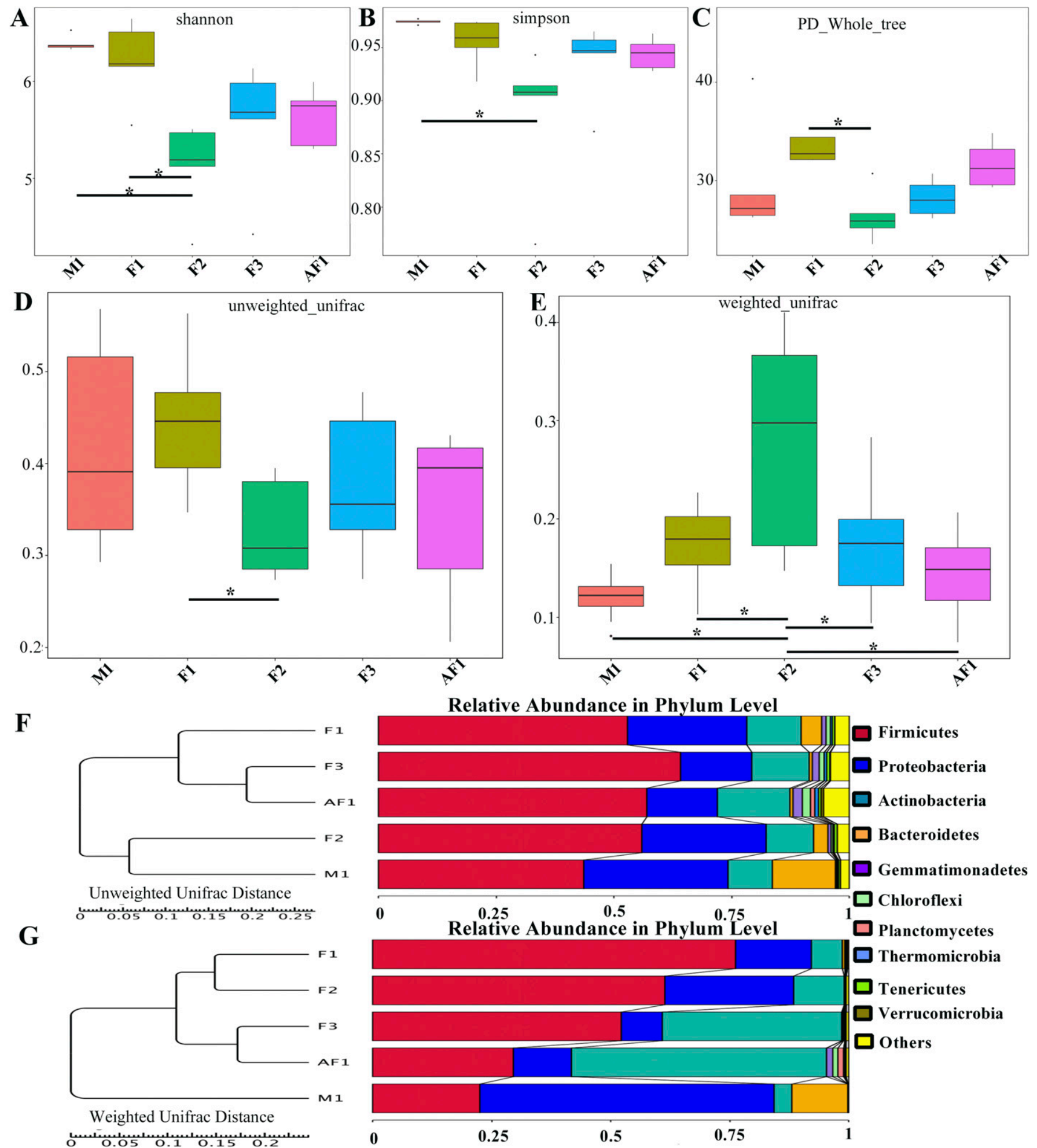

Fig. 3. Alpha and beta diversity of bacterial communities in the wheat straw substrates. The parameters of alpha diversity in the five stages are listed in A-C. The parameters of beta diversity in the five stages are listed in $\mathbf{D}$ and $\mathbf{E}$. Based on unweighted and weighted unifrac distance, the cluster dendrogram of relative abundance in phylum level are listed in $\mathbf{F}$ and $\mathbf{G}$.

and the latter by the family Vulgatibacteraceae. The distinct families in F1, F2, and F3 were Bacillaceae, Family XVIII and Xanthomonadaceae, and Ruminococcaceae, respectively.

The ternary plot analysis (Fig. 4B-E), showed that the Thermobispora and Thermopolyspora genera were represented in AF1 and F3 compared with F1, F2, or M1 stages. Acinetobacter and Sphingobacterium were the top two genera in M1, and Bacillus was the topmost genus in F1.

Top fungal phyla and genera. The dominant phyla and genera of fungi in the five fermentation stages are shown in Fig. 5A and B. Ascomycota and Basidiomycota were the top two phyla in all stages except for AF1, and Chytridiomycota was represented in the F2, F3, and AF1 stages. Pyrenophora, Alternaria, and Sporobolomyces were the predominant genera in stage M1; Gibellulopsis and Alternaria dominated F1; Microidium, Chaetomium, Gonapodya, Gibellulopsis, and Trichoderma 


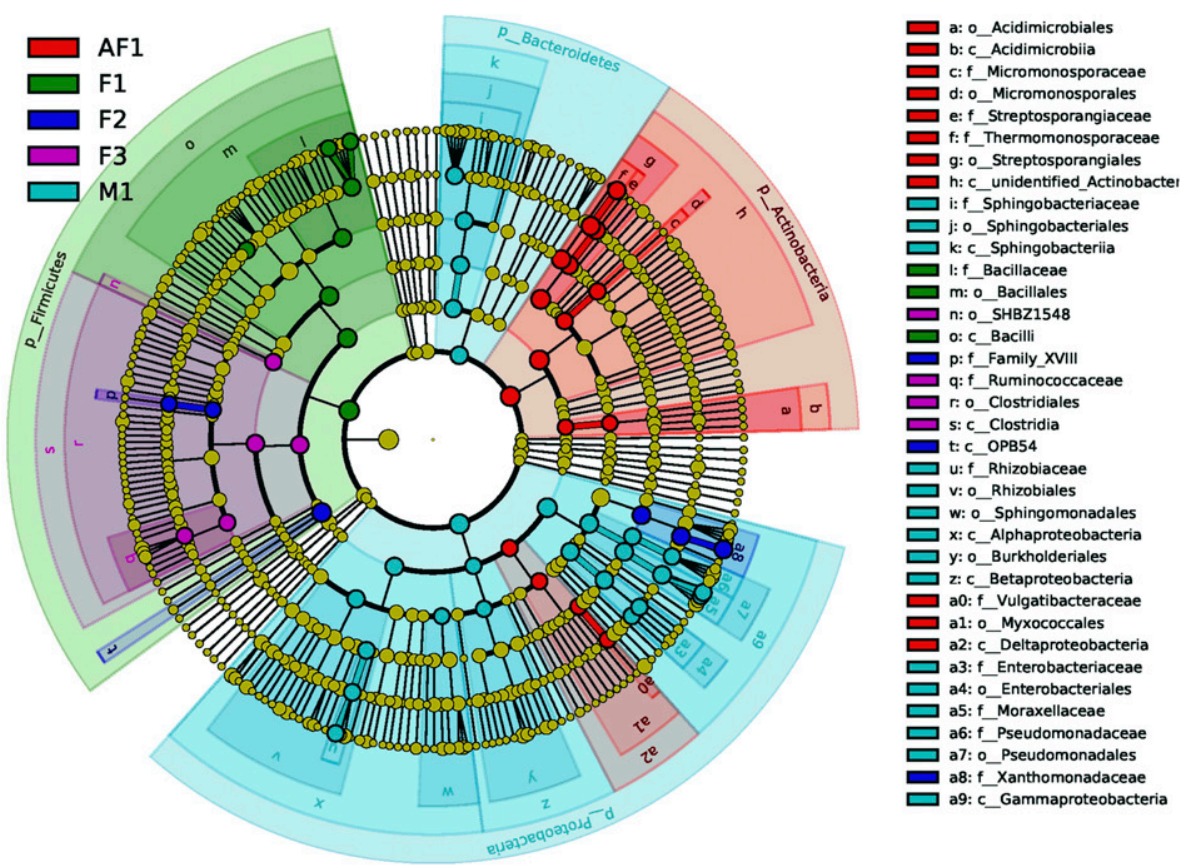

B

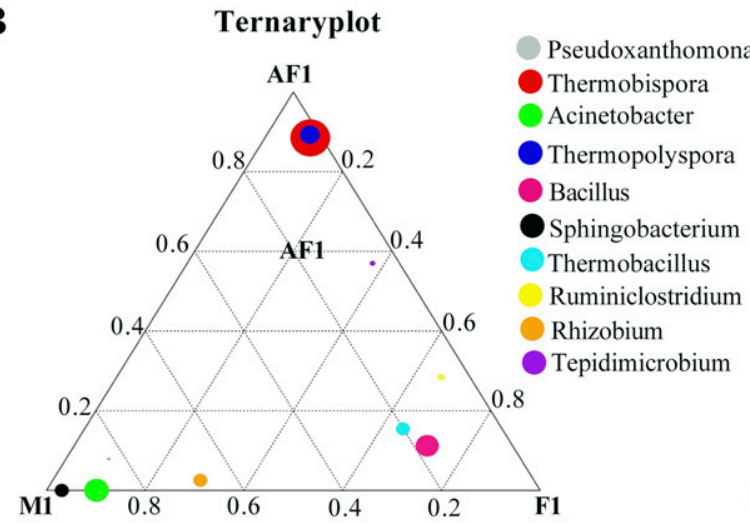

C

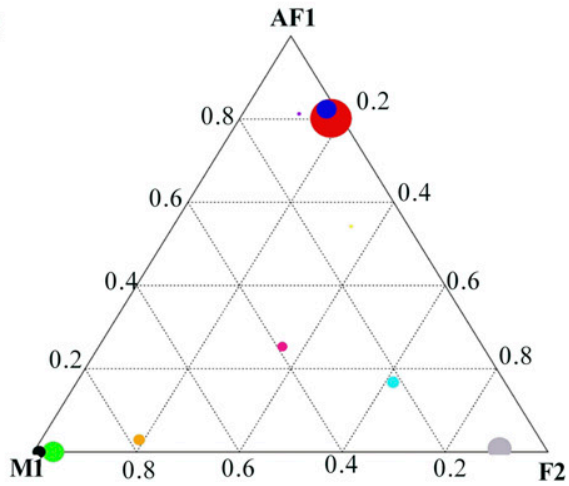

D
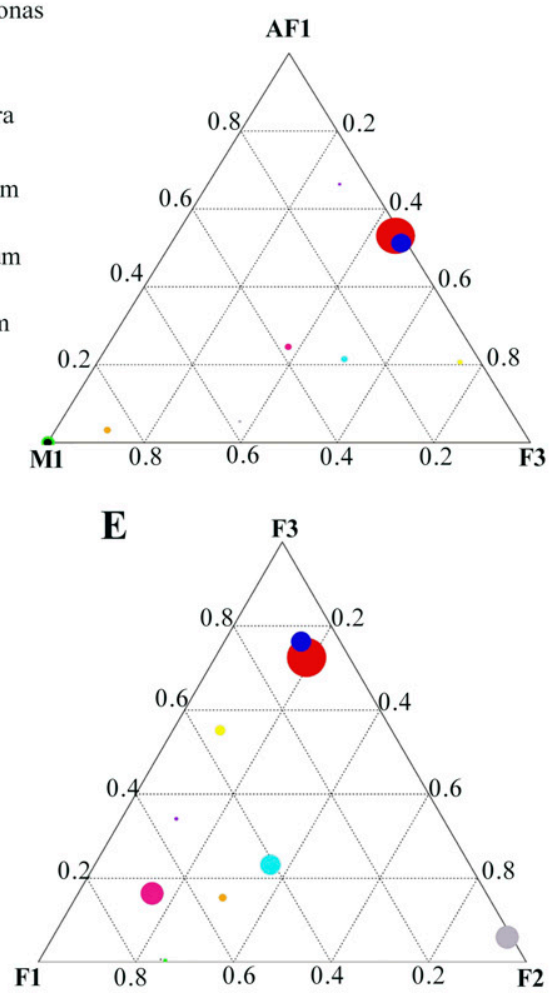

Fig. 4. The cladogram linear discriminant analysis with effect size analysis (A) and ternary plot of bacterial communities (B-E).

dominated F2; Chaetomium, Gonapodya, and Gibellulopsis were predominant in F3; and Microidium, Chaetomium, Mycothermus, and Gonapodya were represented in the AF1 stage. On the basis of these data, greater fungal diversity was observed in the $\mathrm{F} 2$ and $\mathrm{F} 3$ stages. It is also worth mentioning that $75 \%$ relative abundance of fungi were unknown in F1.
OTUs analysis of fungal communities. There were 384 OTUs in common among the five stages (Fig. 5C). The number of unique OTUs in stages M1, F1, F2, F3, and AF1 were 90, 391, 265, 195, and 328, respectively. Only 594 OTUs were shared between M1 and AF1 (Fig. 5D), and 1054 and 454 OTUs were unique to M1 and AF1, respectively. Meanwhile, 603 unique OTUs were common among the stages F1, F2, and F3 (Fig. 5E). In addition, 641, 530, and 370 OTUs were unique to F1, F2, and F3, respectively.

$P C A$ and NMDS plots of fungal communities. The PCA plot distinguished the F2 and AF1 stages from the other three stages, which were clustered together (Fig. 5F). Similarly, the NMDS plot showed 


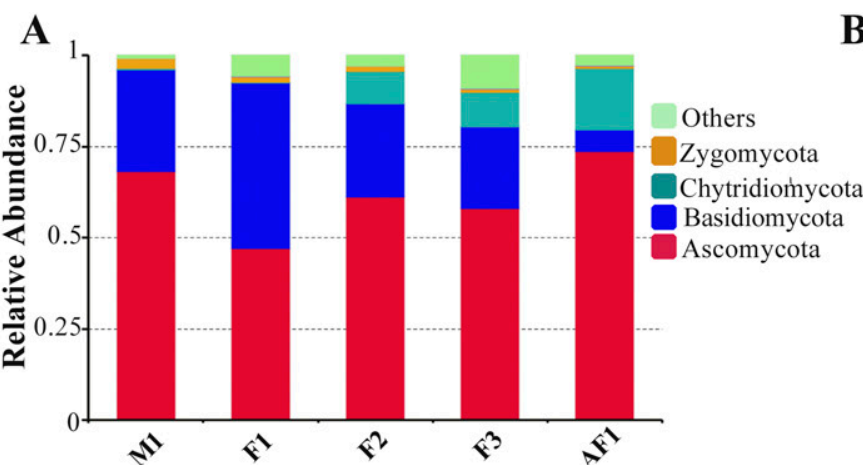

C

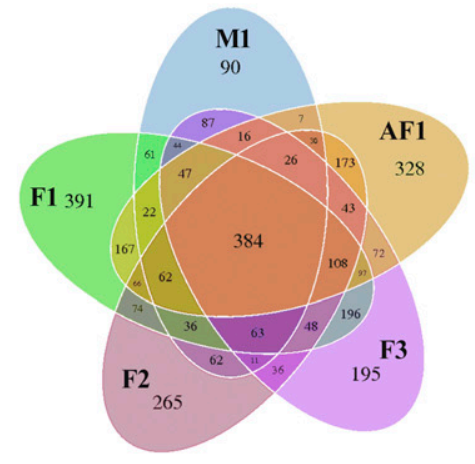

F

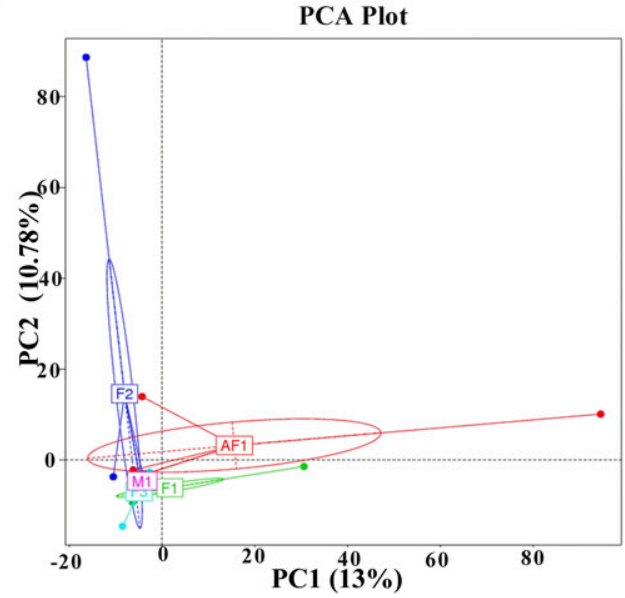

B
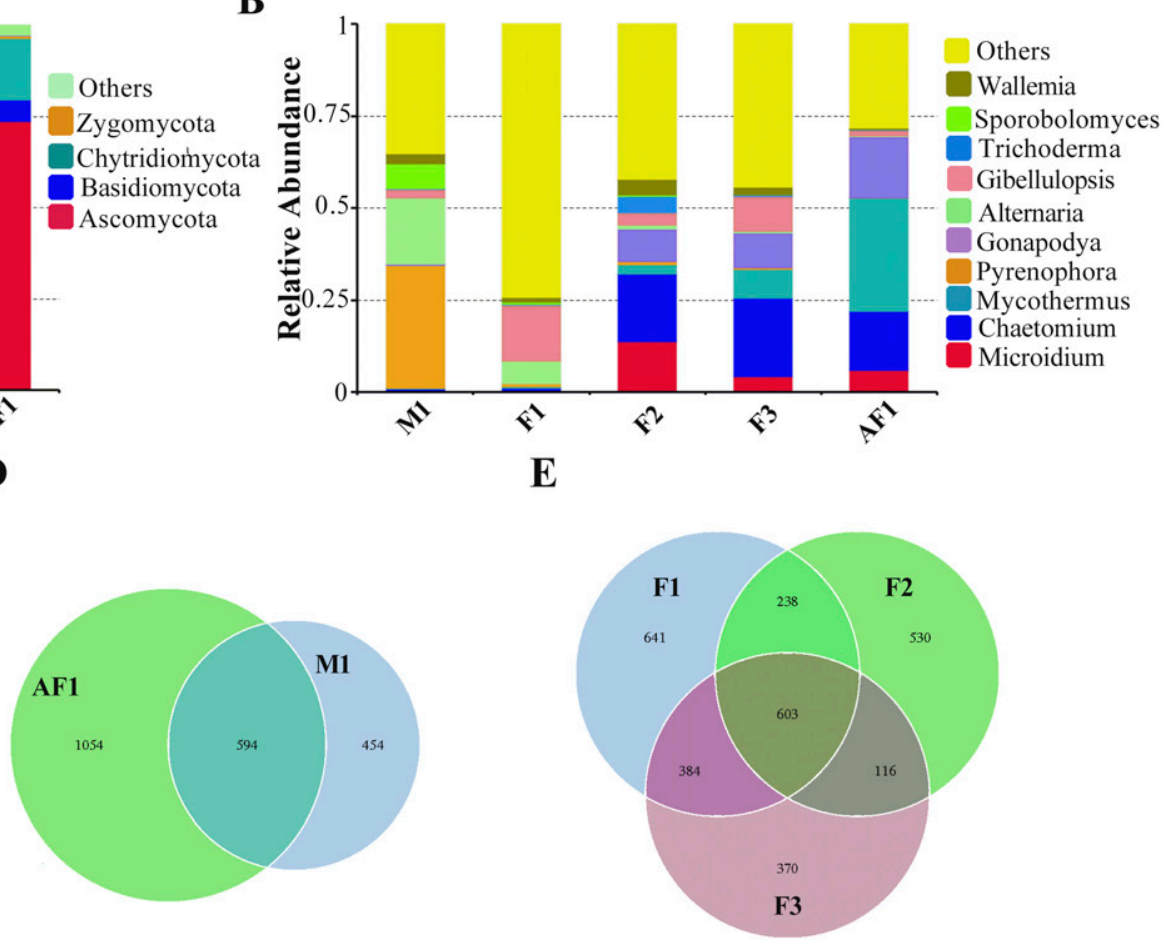

NMDS Plot

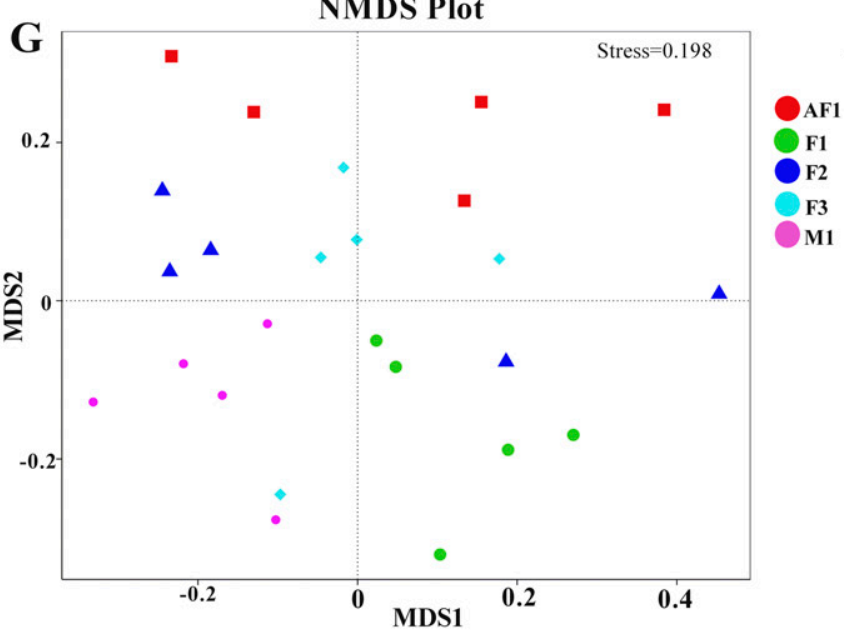

Fig. 5. Top 10 phyla (A) and genera (B) of fungal communities in wheat straw substrates. Operational taxonomic unit analysis of fungal communities in wheat straw substrates $(\mathbf{C}-\mathbf{E})$. Principal component analysis (PCA) (F) and nonmetric multidimensional scaling (NMDS) (G) plots of fungal communities in wheat straw substrates.

that samples of F2 and AF1 were more dispersed than those of the other stages (Fig. 5G).

Alpha and beta diversity of the fungal communities. Figure 6A-D lists the alpha diversity of fungi in the different stages, and Fig. $6 \mathrm{E}$ and $\mathrm{G}$ list the beta diversity. No significant differences were observed in the alpha diversity (Shannon index, Simpson index, PD_Whole tree and observed species) of fungi $(P>0.05)$. On the basis of the unweighted UniFrac, M1 had a significantly lower beta diversity of fungi than F2 $(P<$ $0.05)$ and had a decreasing trend than $\operatorname{AF} 1(P=$ $0.086)$. In contrast, in the weighted UniFrac, F2 had a significantly greater beta diversity of fungi than M1 or F3 $(P<0.05)$. Furthermore, the cluster dendrogram based on weighted UniFrac indicated that F1 samples were closer to AF1 (Fig. 6F), and samples $\mathrm{F} 1, \mathrm{~F} 2$, and F3 were closer to AF1 than M1 (Fig. 6H).

Ternary plot and LEfSe analysis of fungi. Figure 7A-D shows that the Chaetomium, Mycothermus, and Gonapodya genera were represented in AF1 compared with M1, with the latter two genera also being closer to AF1 compared with F1, F2, or F3. Furthermore, Pyrenophora and Alternaria were representative of M1 compared with AF1, F1, F2, or F3. Compared with F1, Chaetomium and Gonapodya were closer to F2 and F3 (Fig. 7D). Furthermore, Gibellulopsis was closer to F1 and F3, compared with F2 samples.

LEfSe analysis showed that the distinct species in AF1 were Mycothermus thermo- philus, Gonapodya polymorpha, and Phaeophleospora_eugeniae (Fig. 7E). In M1 the fungal species were Chaetomium thermophilum, Pyrenophora teres, Alternaria tenuissima, and Pyrenophora graminea, and F3 was represented by Sporobolomyces ruberrimus. And in F1, Capnodiales were the prominent order (Supplemental Fig. 1B).

\section{Discussion}

Substrate preparation is the most critical step in A. bisporus cultivation, which has led to decades of research on the degradation of wheat straw. Composting for mushroom substrate involves the synergistic action of bacteria and fungi. The decomposition of cellulosic plant material and microbial 

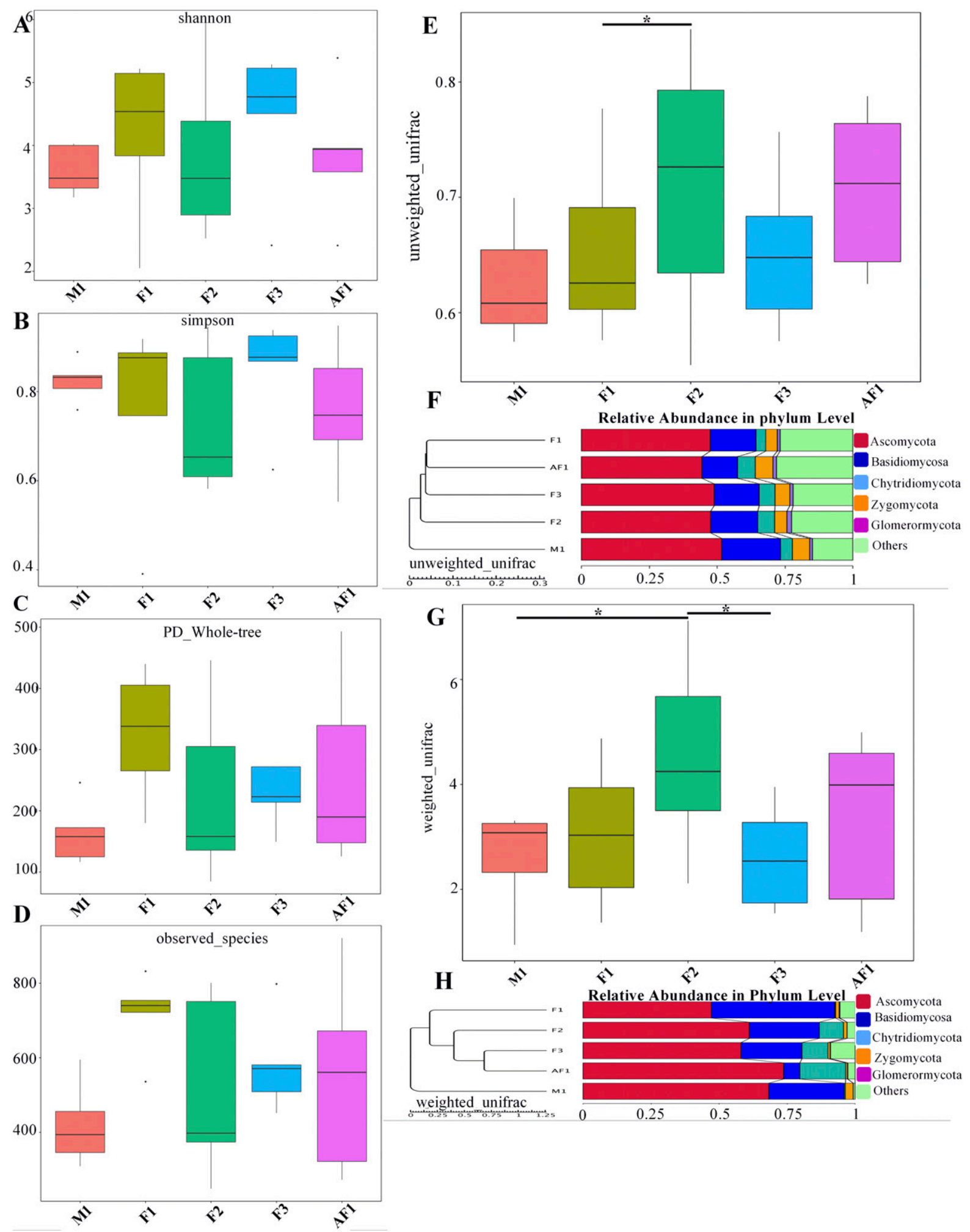

0.25

0.5

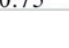

Fig. 6. Alpha and beta diversity of fungal communities in the wheat straw substrates. The parameters of alpha diversity in the five stages are listed in A-D. The parameters of beta diversity in the five stages are listed in $\mathbf{E}$ and $\mathbf{G}$. Based on unweighted and weighted unifrac distance, the cluster dendrogram of relative abundance in phylum level are listed in $\mathbf{F}$ and $\mathbf{H}$.

activity are required for mushroom substrate production (Zhang et al., 2014). Few studies have focused on bacteria from different composting stages, although the structure and diversity of microflora have not been well characterized (Singh et al., 2012; Vajna et al., 2012). Valdez-Vazquez et al. (2017) reported that wheat straw compost was composed of hydrogen producers of the phyla Firmicutes and Proteobacteria. Phyla of Proteobacteria, Firmicutes, Bacteroidetes, and Actinobacteria also have been reported to be found in compost (Jurado et al., 2014; Partanen et al., 2010). Our study suggests that
Firmicutes, Proteobacteria, and Actinobacteria are the predominant phyla in different fermentation stages. In addition, the orders of Bacillales, Clostridiales, Actinomycetales, and Thermoanaerobacterales have been reported to be present throughout the composting of plant biomass (Antunes et al., 2016). 
A

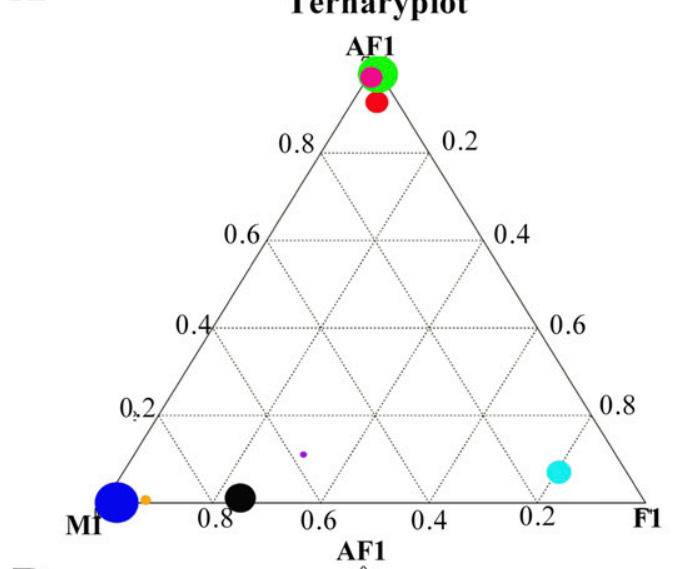

B

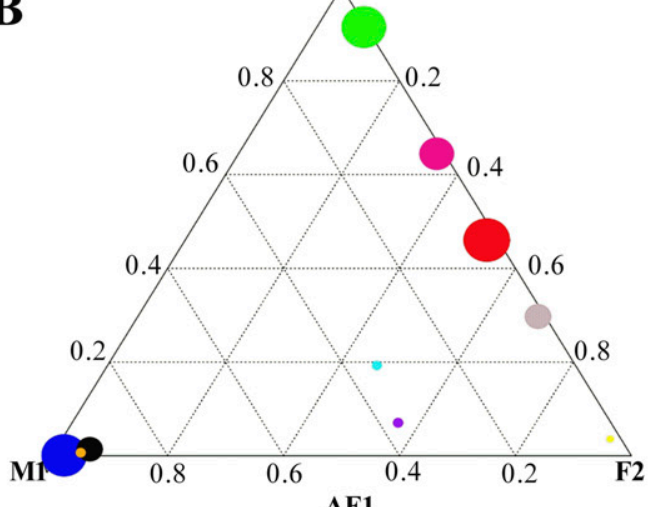

C

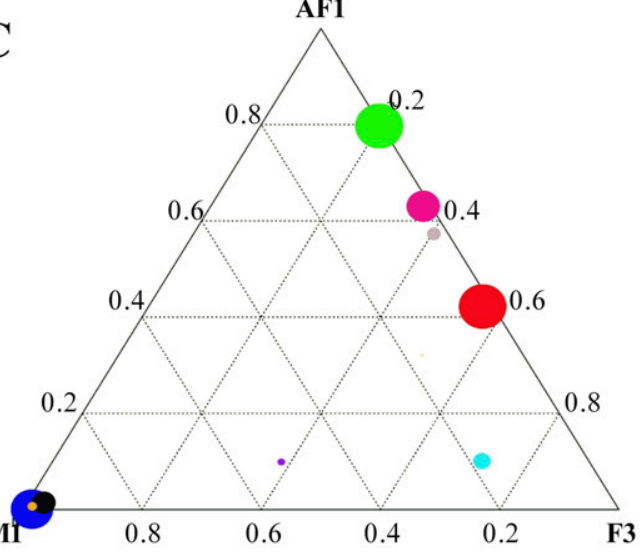

Microdium

Chaetomium

Mycothermus

Pyrenophora

Gonapodya

Alternaria

Gibellulopsis

Trichoderma

Sporobolomyces

Wallemia

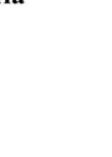

D
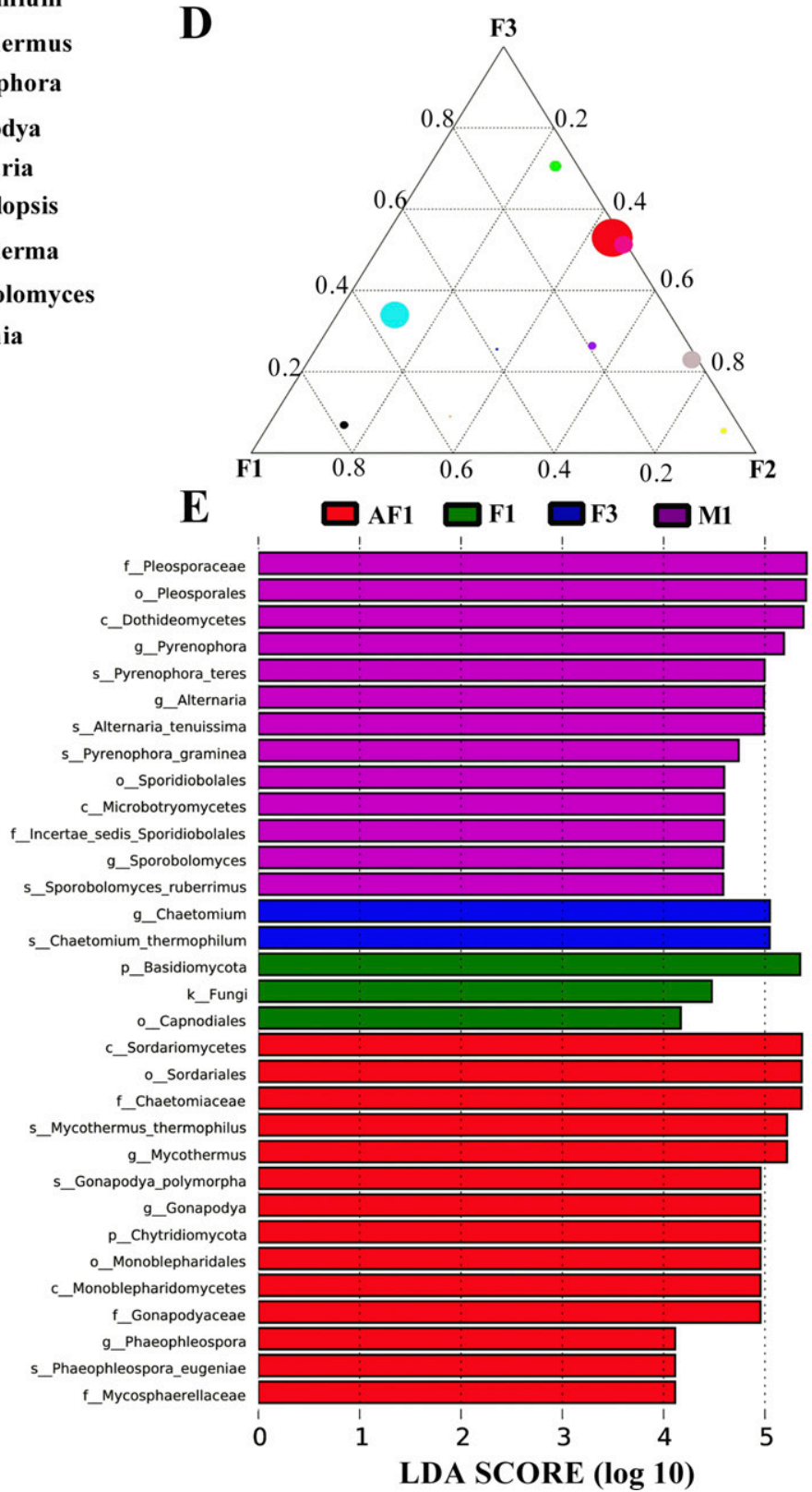

Fig. 7. The ternary plot (A-D) and linear discriminant analysis with effect size analysis $(\mathbf{E})$ of fungal communities in the wheat straw substrates. LDA $=$ linear discriminant analysis.

Similarly, the predominant orders we observed were Bacillales, Clostridiales, Rhizobiales, and Streptosporangiales, with the latter increasing over composting time. Furthermore, we observed that the relative abundance of Firmicutes decreased and Actinobacteria increased over time. Studies reported that the Actinobacteria, which are cellulose decomposers, always exist and peak in the later stages of composting, suggesting a critical role of Actinomycetes in the compost ecosystem (Wang et al., 2014; Zhang et al., 2014). In addition, thermotolerant Actinobacteria are observed in thermophilic conditions (Zhang et al., 2014). Tortora et al. (2007) also reported that thermophilic Actinobacteria can survive at relatively high temperatures ranging from 40 to $80{ }^{\circ} \mathrm{C}$. Although the diversity of Actinomycetes has been found to increase with the composting process (Peters et al., 2000), the Actinobacteria in mushroom substrates have not been identified (Vajna et al., 2012). However, the composition of Actinobacterial communities have been reported to vary during various stages of composting (Xiao et al., 2011).

In our study, PCA and NMDS plots revealed that the bacterial communities of the five stages of composting were clearly clustered according to the different stage when the samples were collected. The relative abundance of top 10 genera in the five fermentation stages were different from each other, except at F3 and after-fermentation.
The temperature of substrate for $A$. bisporus cultivation changes from $80^{\circ} \mathrm{C}$ in phase I to between 50 and $60^{\circ} \mathrm{C}$ in phase II, and finally drops to $45^{\circ} \mathrm{C}$ in phase III, which impacts the composition of microflora (Gerrits, 1988; Grimm and Wösten, 2018). Meanwhile, the alpha diversity of fermentative stage II was lower than that of the other stages, suggesting poorer microflora in stage II. We speculate that the diversity of micro-organisms in substrate was decreased by the heat stress of phase I. In this study, LEfSe and ternary plots revealed that the Thermobispora and Thermopolyspora genera were predominant at the fermentation stage III and after-fermentation stage of wheat straw substrate. Vajna et al. (2012) reported that Bacillus, Geobacillus, 
Ureibacillus, Pseudoxanthomonas, and Thermobispora appeared at the end of composting for oyster mushroom substrate, and Thermus, Bacillus, Geobacillus, Thermobacillus, and Ureibacillus were predominant in the mature substrate. The type of cultivation, components of substrate, fermentation time, and type of wheat straw material (ligninolytic composition) were identified as important factors that influence the diversity of microorganisms in the substrate.

In thermophilic fermentation processes, bacteria are responsible for initiating degradation of materials, whereas fungi begin to play a role during the cooling and curing stages (Dhaeseleer et al., 2013; LópezGonzález et al., 2015; Neher et al., 2015). Fungi occupy an important position in biological biomass pretreatment due to their strong ligninolytic activity (Stajić et al., 2016). Studies found that white-rot fungi could effectively degrade lignin by producing extracellular enzymes, such as lignin peroxidase, manganese peroxidase, and laccase, and the fungal strain, substrate, and culture conditions influence the pretreatment efficiency (Wan and Li, 2012). In our study, the F1 stage had the fewest types of the top 10 identified fungal genera, and no differences in fungi were observed in the alpha diversity of five stages. Antunes et al. (2016) reported that fungi are not detected above $65{ }^{\circ} \mathrm{C}$, which supports our observations. However, over time the relative abundance of Chytridiomycota phylum increased in the fermentation of wheat straw substrates, and Mycothermus thermophilus, Gonapodya polymorpha, and Pyrenophleospora eugeniae were the predominant species in the afterfermentation stage. Kertesz and Thai (2018) reported that the thermophilic fungus $\mathrm{Myco}$ thermus thermophilus, Thermophilic proteobacteria, and Actinobacteria play a key role in the processes of composting. Because of the limited research about fungal communities in composting, more studies focusing on this aspect are needed to better understand the wheat straw substrate of $A$. bisporus.

To conclude, on the one hand, the microflora diversity of substrates at different fermentation stages changed dramatically, which included the alpha and beta diversity (considering the bacterial types and relative abundance) of F2 and that differed dramatically from the other stages. It is also worth noting that the relative abundance of Firmicutes phylum decreased, whereas that of the Actinobacteria increased over time. Members of Micromonosporaceae, Streptosporaceae, Vulgatibacteraceae, and Thermomonosporaceae comprised distinguished microbiota of the substrate at after-fermentation stage. However, Microidium, Chaetomium, Mycothermus, and Gonapodya comprised the predominant fungi at after-fermentation phase. Thus, considering the relative abundance, the Chytridiomycota ratio increased, whereas that of Basidiomycota decreased over time, with the exception of the material phase and Mycothermus thermophilus,
Gonapodya polymorpha, and Pyrenophleospora eugeniae were the distinguished fungi in AF1.

\section{Literature Cited}

Antunes, L.P., L.F. Martins, R.V. Pereira, A.M. Thomas, D. Barbosa, L.N. Lemos, G.M. Silva, L.M. Moura, G.W. Epamino, L.A. Digiampietri, K.C. Lombardi, P.L. Ramos, R.B. Quaggio, J.C. de Oliveira, R.C. Pascon, J.B. Cruz, A.M. da Silva, and J.C. Setubal. 2016. Microbial community structure and dynamics in thermophilic composting viewed through metagenomics and metatranscriptomics. Sci. Rep. 6:38915.

Ćilerdžić, J., M. Galić, J. Vukojević, I. Brčeski, and M. Stajić. 2017. Potential of selected fungal species to degrade wheat straw, the most abundant plant raw material in Europe. BMC Plant Biol. 17(Suppl 2):249.

Dhaeseleer, P., J.M. Gladden, M. Allgaier, P.S. Chain, S.G. Tringe, S.A. Malfatti, J.T. Aldrich, C.D. Nicora, E.W. Robinson, L. Paša-Tolić, P. Hugenholtz, B.A. Simmons, and S.W. Singer. 2013. Proteogenomic analysis of a thermophilic bacterial consortium adapted to deconstruct switchgrass. PLoS One 8(7):e68465.

Gerrits, J.P.G. 1988. Nutrition and compost, p. 2972. In: L.J.L.D. Van Griensven (ed.). The cultivation of mushrooms. Darlington Mushroom Laboratories, Ltd., Peterborough, UK.

Grimm, D. and H.A.B. Wösten. 2018. Mushroom cultivation in the circular economy. Appl. Microbiol. Biotechnol. 102:7795-7803.

Hanafi, F.H.M., S. Rezania, S.M. Taib, M.F.M. Din, M. Yamauchi, M. Sakamoto, H. Hara, J. Park, and S.S. Ebrahimi. 2018. Environmentally sustainable applications of agro-based spent mushroom substrate (SMS): An overview. J. Mater. Cycles. Waste. 20(3):13831396.

Harith, N., N. Abdullah, and V. Sabaratnam. 2014. Cultivation of Flammulina velutipes mushroom using various agro-residues as a fruiting substrate. Pesqui. Agropecu. Bras. 49(3):181188.

Hua, B., J. Dai, B. Liu, H. Zhang, X. Yuan, X Wang, and Z. Cui. 2016. Pretreatment of non-sterile, rotted silage maize straw by the microbial community mcl increases biogas production. Bioresour. Technol. 216:699 705.

Jurado, M., M.J. López, F. Suárez-Estrella, M.C. Vargas-García, J.A. López-González, and J. Moreno. 2014. Exploiting composting biodiversity: Study of the persistent and biotechnologically relevant microorganisms from lignocellulosebased composting. Bioresour. Technol. 162 (6):283-293.

Kertesz, M.A. and M. Thai. 2018. Compost bacteria and fungi that influence growth and development of agaricus bisporus, and other commercial mushrooms. Appl. Microbiol. Biotechnol. 102(4):1-12.

López-González, J.A., F. Suárez-Estrella, M.C. Vargas-García, M.J. López, M.M. Jurado, and J. Moreno. 2015. Dynamics of bacterial microbiota during lignocellulosic waste composting: Studies upon its structure, functionality and biodiversity. Bioresour. Technol. 175:406416.

Neher, D.A., T.R. Weicht, and P. Dunseith. 2015. Compost for management of weed seeds, pathogen, and early blight on brassicas in organic farmer fields. Agroecol. Sust. Food. 39:3-18.

Pala, S.A., A.H. Wani, and R.H. Mir. 2012. Yield performance of Pleurotus sajorcaju on different agro-based wastes. Ann. Biol. Res. 3(4):19381941.

Partanen, P., J. Hultman, L. Paulin, P. Auvinen, and M. Romantschuk. 2010. Bacterial diversity at different stages of the composting process. BMC Microbiol. 10(1):94.

Peters, S., S. Koschinsky, F. Schwieger, and C.C. Tebbe. 2000. Succession of microbial communities during hot composting as detected by PCRsingle-strand-conformation polymorphism-based genetic profiles of small-subunit rRNA genes. Appl. Environ. Microbiol. 66(3):930-936.

Rinker, D.L. 2017. Spent mushroom substrate uses, p. 427-454. In: D. Cunha Zied and A. Pardo-Giménez (eds.). Edible and medicinal mushrooms: Technology and applications. Wiley-Blackwell, Hoboken, NJ.

Rouches, E., M.F. Dignac, S. Zhou, and H. Carrere. 2017. Pyrolysis-gc-ms to assess the fungal pretreatment efficiency for wheat straw anaerobic digestion. J. Anal. Appl. Pyrolysis 123:409418.

Saha, B.C. and M.A. Cotta. 2006. Ethanol production from alkaline peroxide pretreated enzymatically saccharified wheat straw. Biotechnol. Prog. 22:449-453.

Saparrat, M.C.N. and F. Guillén. 2005. Ligninolytic ability and potential biotechnology application of the South American fungus Pleurotus laciniatocrenatus. Folia Microbiol. (Praha) 50:155-160.

Singh, A.V., A. Sharma, and B.N. Johri. 2012. Phylogenetic profiling of culturable bacteria associated with early phase of mushroom composting assessed by amplified rDNA restriction analysis. Ann. Microbiol. 62(2):675-682.

Šnajdr, J. and P. Baldrian. 2006. Production of lignocellulose-degrading enzymes and changes in soil bacterial communities during the growth of Pleurotus ostreatus in soil with different carbon content. Folia Microbiol. (Praha) 51:579-590.

Stajić, M., J. Vukojević, I. Milovanović, J. Ćilerdžić, and A. Knežević. 2016. Role of mushroom Mn-oxidizing peroxidases in biomass conversion, p. 251-269. In: V.K. Gupta (ed.). Microbial enzymes in bioconversion of biomass. Springer International Publishing AG, Basel, Switzerland.

Straatsma, G., R.A. Samson, T.W. Olijnsma, H.J.M.O.D. Camp, J.P.G. Gerrits, and L.J.L.D. Van Griensven. 1994. Ecology of thermophilic fungi in mushroom compost, with emphasis on scytalidium thermophilum and growth stimulation of agaricus bisporus mycelium. Appl. Environ. Microbiol. 60(2):454458.

Sun, W., E. Xiao, Z. Pu, V. Krumins, Y. Dong, B. $\mathrm{Li}$, and M. Hu. 2018. Paddy soil microbial communities driven by environment- and microbe-microbe interactions: A case study of elevation-resolved microbial communities in a rice terrace. Sci. Total Environ. 612:884-893.

Tejirian, A. and F. Xu. 2010. Inhibition of cellulase-catalyzed lignocellulosic hydrolysis by iron and oxidative metal ions and complexes. Appl. Environ. Microbiol. 76:7673-7682.

Tortora, G.J., B.R. Funke, and C.L. Case. 2007. Microbiology: An introduction. Pearson Benjamin Cummings, San Francisco, CA.

Treuer, T.L., J.J. Choi, D.H. Janzen, W. Hallwachs, D. Peréz-Aviles, A.P. Dobson, J.S. Powers, L.C. Shanks, L.K. Werden, and D.S. Wilcove. 2018. Low-cost agricultural waste accelerates tropical forest regeneration. Restor. Ecol. 26 (2):275-283.

Vajna, B., D. Szili, A. Nagy, and K. Márialigeti. 2012. An improved sequence-aided T-RFLP analysis of bacterial succession during oyster 
mushroom substrate preparation. Microb. Ecol. 64(3):702-713.

Valdez-Vazquez, I., A.L. Morales, and A.E. Escalante. 2017. History of adaptation determines short-term shifts in performance and community structure of hydrogen-producing microbial communities degrading wheat straw. Microb. Biotechnol. 10(6):1569-1580.

Wan, C. and Y. Li. 2012. Fungal pretreatment of lignocellulosic biomass. Biotechnol. Adv. 30:1447-1457.

Wang, C., X. Guo, H. Deng, D. Dong, Q. Tu, and W. Wu. 2014. New insights into the structure and dynamics of actinomycetal community during manure composting. Appl. Microbiol. Biotechnol. 98(7):3327-3337.

Xiao, E., V. Krumins, T. Xiao, Y. Dong, S. Tang, Z. Ning, Z. Huang, and W. Sun. 2016. Depthresolved microbial community analyses in two contrasting soil cores contaminated by antimony and arsenic. Environ. Pollut. 221:244-255.

Xiao, Y., G.M. Zeng, Z.H. Yang, Y.H. Mac, C. Huang, Z.Y. Xu, J. Huang, and C.Z. Fan. 2011. Changes in the actinomycetal communities duringcontinuous thermophilic composting as revealed by denaturing gradient gel electropho- resis and quantitative PCR. Bioresour. Technol. 102:1383-1388.

Xiao, Z., M. Lin, J. Fan, Y. Chen, C. Zhao, and B. Liu. 2018. Anaerobic digestion of spent mushroom substrate under thermophilic conditions: Performance and microbial community analysis. Appl. Microb. Biot. 102(1):499-507.

Zhang, X., Y. Zhong, S. Yang, W. Zhang, M. Xu, A. Ma, G. Zhuang, G. Chen, and W. Liu. 2014. Diversity and dynamics of the microbial community on decomposing wheat straw during mushroom compost production. Bioresour. Technol. 170(5):183-195. 

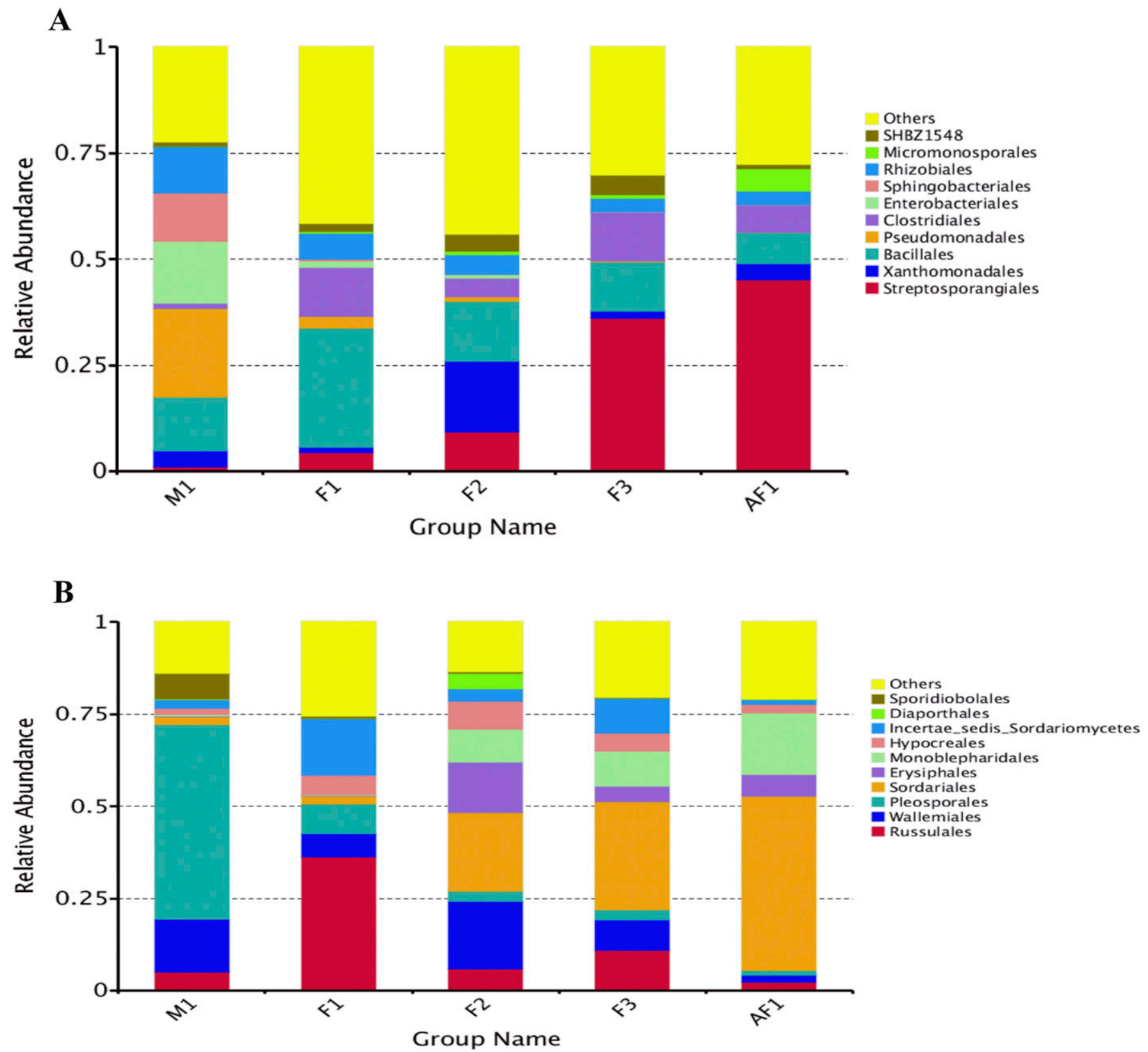

Supplemental Fig. 1. Top ten orders (A) and classes (B) of fungal communities in wheat straw substrates. 